\title{
Biotechnological efforts for the propagation of Quercus lusitanica Lam., an endangered species
}

\section{Trees: Structure and Function vol 31: 1571-1581, 2017}

San José MC, Martínez MT, Cernadas MJ, Montenegro R, Mosteiro F, Corredoira E

Group of Biotechnology and Forestry Improvement. Instituto de Investigaciones Agrobiológicas de Galicia. CSIC. Avda. de Vigo s/n. 15705 Santiago de Compostela, Spain.

E-mail: sanjose@iiag.csic.es

\begin{abstract}
This is the first time that a simple protocol is presented for the micropropagation and short-term conservation of Quercus lusitanica, an endemic and endangered species that is found in very restricted habitats of the Iberian Peninsula and North Africa. Branch segments from 15-20-year-old trees were forced-flushed, and the forced shoots were used as a source of explants for culture initiation. The best multiplication rates were obtained on Woody Plant Medium (WPM) supplemented with $0.1 \mathrm{mg} 1^{-1}$ benzyladenine for the genotype CDL, or $0.2 \mathrm{mg} \mathrm{l}^{-1}$ benzyladenine, $0.5 \mathrm{mg} \mathrm{l}^{-1}$ indole acetic acid and $0.2 \mathrm{mg}$ $\mathrm{I}^{-1}$ zeatin in the case of the genotype SC1. Although the cultivation of shoots in the horizontal position improved the proliferation rates, the shoot vitrification was increased under these conditions. The best rooting rates were obtained on half-strength WPM supplemented with $3 \mathrm{mg} \mathrm{l}^{-1}$ indole-3-butyric acid for 7 days with subsequent transfer to auxin-free medium supplemented with $0.4 \%$ activated charcoal. An initial 5-day dark period was detrimental to the quality of regenerated plantlets. Well-acclimatized plantlets were transferred to the field with a $70 \%$ survival rate.
\end{abstract}

Keywords: dwarf oak, endangered species, micropropagation, Quercus lusitanica, short-term conservation

Author contribution statement: MC San José and E Corredoira designed the research, analyzed the data and wrote the paper. MT Martínez, MJ Cernadas, R Montenegro and F Mosteiro conducted the research. All authors have read and approved the final manuscript. 
Key message: A protocol is presented for the micropropagation and short-term conservation of Quercus lusitanica Lam.

Conflict of interest: The authors declare that they have no conflict of interest

\section{Introduction}

The genus Quercus belongs to the family Fagaceae, which is mainly found in the northern hemisphere, and is of great ecological and economic value. It includes deciduous and evergreen species that extend from cold latitudes to tropical Asia and the Americas. The trees of the different species are very important from both an economic and ecological perspective (Vieitez et al. 2012). This genus includes Quercus lusitanica Lam., commonly known as dwarf oak, a small bush that rarely grows more than $3 \mathrm{~m}$ high. It grows on hills of up to $600 \mathrm{~m}$ altitude in a mild climate. Its area of distribution is currently restricted to 3 populations, one of which is situated in North Africa (Morocco). The other two are located in west of the Iberian Peninsula, one of which is an area in southern Portugal and western Andalusia, whilst the other is limited to single location in the northwest of the Iberian Peninsula (La Coruña, Spain) where its presence is scarce. This last population is situated in Monte Pindo. The area forms part of the Nature Network, and as such is catalogued as a "Special Protection Area of Natural Values". This peculiar geographic distribution, as well as its reduced presence, has led to its inclusion in the Galician Catalogue of Endangered Species (DOG 155; 12/08/2011) and it is also included in the Extremadura Catalogue of Endangered Species (Vázquez et al. 2010), and in the Red List of Andalusia (Cabezudo et al. 2005). The reduced number of specimens and deterioration of its habitat have now led to it being classified as an endangered species, and considered an Iberian-western Tangiers endemism. As well as its ecological value, Muliawan et al. (2006) reported the in vitro inhibitory potential of a crude extract from seeds of this species on the replication of dengue virus type 2 (DEN-2). Its extract is also found in the composition of different patented topical skin preparations (Patents No.EP2705772A1; WO 2013131752A2).

The number of endangered plant species in the world has increased in recent years due to anthropogenic and environmental pressures. Numerous species are described as endangered, and integrated programs are required to protect and preserve current biodiversity (Fay 1992; Sarasan et al. 2006). Special attention must be given to endemic flora, which is a critical target in conservation strategies, as it is restricted to small areas. In these cases, clonal propagation could be a feasible strategy for increasing the number of individuals ex situ, and in vitro cultures could be an efficient method to achieve this objective. The 
importance of the in vitro culture of plant tissues in the conservation of endemic, rare, and endangered species has increased in recent years. The use of biotechnological tools is an important way to safeguard the germplasm of endangered plants, and has become increasingly popular for conservation purposes (Guo et al. 2007; Piovan et al. 2010; Pence 2013; Hill et al. 2015). The use of these tools is currently being promoted because habitat degradation makes the development of in situ conservation programs difficult.

The biotechnological techniques used for ex situ conservation are seen as an improvement on traditional conservation methods and provide an extra means to protect wild resources (Fay 1992). These ex situ strategies are especially important in small plant populations, or in those species with low seed output and/or viability (Wildi et al. 1998). In vitro culture enables large amounts of individuals to be rapidly produced from small amounts of plant material, and thus scarcely affects wild populations. In addition, tissue culture and the promotion of organogenic processes for in vitro propagation are common methods of increasing plant material for use in germplasm conservation protocols, or even in re-introductions, if considered appropriate. The most widely used methods are the development of preformed axillary buds from shoots (Bunn 2005; Jayaram and Prasad 2007). These techniques were initially applied to different oak species because they provide appropriate tools for the rapid production of genotypes to regenerate trees with desired traits, and to capture all of the genetic superiority without involving any gene segregation. They would alleviate the lack of acorn production of selected oak trees on a yearly basis, as well as the difficulties in producing offspring with desired traits, difficulties in storing acorns, and the low rooting capacity of stem cuttings (Vieitez et al. 2012). Although there are numerous publications on the micropropagation of other species of the Quercus genus, none of them make reference to the species that is the purpose of this study. Furthermore, there are still no data on its reproductive biology. There are only data regarding Portuguese populations, for which reproductive success has not been contemplated, although it has been shown that the germination capacity of the species is acceptable (Fernández Rodríguez et al. 2005).

In the present study, we describe for the first time a simple system for the rapid clonal propagation of $Q$. lusitanica via in vitro proliferation of axillary shoots. The main objectives of this work were: to study the initiation and stabilization stages of shoot cultures derived from $Q$. lusitanica explants; to optimize the shoot proliferation stage by evaluating the effect of different mineral media; and to define the rooting stage of micropropagated shoots for plantlet regeneration of this species. 


\section{Material and methods}

Plant material and culture conditions

Source material consisted of branches collected in December 2015 from two genotypes, CDL and SC1, of Q. lusitanica aged 15-20 years, growing in Monte Pindo (La Coruña, Spain) (Fig. 1A and B), which is considered the most northern population of this species. Segments $20-25 \mathrm{~cm}$ long were cut from the proximal part of branches $(0.5-1.5 \mathrm{~cm}$ thick) and surface sterilized by immersion in a fungicide solution $3.5 \mathrm{~g} \mathrm{l}^{-1}$ (Cuprosan WG, Bayer) for 1 hour. The segments were left to dry for one day and were then inserted upright in moistened perlite, before being forced to flush axillary shoots in a growth chamber at $25^{\circ} \mathrm{C}$ and $80-90 \%$ relative humidity under a $16 \mathrm{~h}$ photoperiod, with a light intensity of $90-100 \mu \mathrm{mol} \mathrm{m}^{-2} \mathrm{~s}^{-}$ ${ }^{1}$ provided by cool-white fluorescent lamps. After 2-3 weeks, the newly sprouted shoots were used as the source of initial explants for in vitro establishment. Flushed shoots 3-10 cm long were stripped of leaves, and their surfaces were disinfected by a 3 -minute immersion in a $0.3 \%$ solution of free chlorine (Millipore $^{\circledR}$ chlorine tablets; Merck, USA) containing 2-3 drops of Tween $80^{\circledR}$ (Merck, USA), after which they were rinsed three times in sterile distilled water. Explants consisting of 5-8 mm shoot tips and nodal segments were cut from the shoots and placed upright in $30 \times 150 \mathrm{~mm}$ culture tubes containing $25 \mathrm{ml}$ of initiation medium. This consisted of GD medium (Gresshoff and Doy, 1972) (Duchefa Biochemie, The Netherlands) supplemented with $0.5 \mathrm{mg} \mathrm{l}^{-1}$ benzyladenine (BA), $30 \mathrm{~g} \mathrm{l}^{-1}$ sucrose and $6.5 \mathrm{~g}^{-1}$ Vitroagar (Pronadisa, Spain), brought to $\mathrm{pH}$ 5.6, and autoclaved at $121^{\circ} \mathrm{C}$ for $20 \mathrm{~min}$. To avoid contact with excreted substances, each explant was moved to the opposite side of its culture tube one day after the initiation of culture. Thereafter, the explants were transferred to fresh initiation medium every 2 weeks. After 8 weeks of culture, the contamination rate, the percentage of explants with sprouting buds (the response rate), and the percentage of explants with shoots $\geq 5 \mathrm{~mm}$ in length were determined for each genotype.

All cultures were kept in a growth chamber with a $16 \mathrm{~h}$ photoperiod, a light intensity of $50-60 \mu \mathrm{mol} \mathrm{m}^{-2} \mathrm{~s}^{-}$

${ }^{1}$ provided by cool-white fluorescent lamps, and with temperatures of $25^{\circ} \mathrm{C}$ light $/ 20^{\circ} \mathrm{C}$ dark.

Shoot multiplication stage 
New shoots longer than $0.5 \mathrm{~cm}$ produced after 8 weeks of culture were excised from the original explants and subcultured to start the proliferation stage. Explants were cultured in $20 \times 150 \mathrm{~mm}$ test tubes containing $16.5 \mathrm{ml}$ of GD medium, but with BA reduced to $0.1 \mathrm{mg}^{-1}$.

Influence of culture medium and type of explant

Nodal and apical explants of the CDL genotype were used to evaluate the dependence of the multiplication rate on the mineral medium. Three different mineral media were used: GD, Woody Plant Medium (WPM; Lloyd and McCown 1980) (Duchefa Biochemie, The Netherlands) and Murashige and Skoog's medium (1962) (Duchefa Biochemie, The Netherlands) with the nitrates reduced by half (MS1/2n). All the media were supplemented with $30 \mathrm{~g} \mathrm{l}^{-1}$ sucrose and $6.5 \mathrm{~g} \mathrm{l}^{-1}$ Vitroagar and $0.1 \mathrm{mg} \mathrm{l}^{-1} \mathrm{BA}$ (pH 5.6).

As explants of the $\mathrm{SC} 1$ genotype would remain in the inactive state when the previously defined protocol was used, the WPM medium for this genotype was supplemented with $0.2 \mathrm{mg} \mathrm{l}^{-1} \mathrm{BA}, 0.5 \mathrm{mg}^{-1}$ indole acetic acid (IAA), and $0.2 \mathrm{mg}^{-1}$ zeatin.

Influence of the orientation of the explant

To investigate the influence of explant orientation on axillary bud growth, uniform shoot explants of the CDL genotype about $20 \mathrm{~mm}$ long, from which the apical $2 \mathrm{~mm}$ had been removed, were used. The explants were placed horizontally in $500 \mathrm{ml}$ glass jars, the glass lids were fixed with plastic wrap (Film Professional, Spain). Each jar contained $70 \mathrm{ml}$ of GD or WPM multiplication medium. The explants were transferred to fresh medium at 2 weeks during the 4-week multiplication cycle.

A total of 12 explants per treatment were used in all multiplication experiments, and all experiments were repeated at least three times. The following variables were determined at the end of the 4-week multiplication cycle: the frequency of responsive explants, i.e. the percentage of explants forming shoots; the total number of shoots; the mean number of shoots $0.5-1.0 \mathrm{~cm}$ long among responsive explants; the mean number of shoots longer than $1 \mathrm{~cm}$ among the responsive explants; and the mean length of the longest shoot in responsive explants.

Rooting stage and acclimatization

For root initiation, shoots 15-20 mm long of the CDL genotype were excised from proliferating cultures 
and their basal halves stripped of leaves. In the first experiment, three mineral media (GD macronutrients reduced to one third strength, and WPM and MS1/2n macronutrients reduced by half) and two indol-3butyric acid (IBA) concentrations $\left(3 \mathrm{mg} \mathrm{l}^{-1}\right.$ for 7 days and $25 \mathrm{mg} \mathrm{l}^{-1}$ for $24 \mathrm{~h}$ ) were evaluated. In all treatments, the shoots were later transferred to rooting medium of the same composition, except for the absence of IBA, for the remainder of the 1-month rooting period. In a second experiment, the effect of activated charcoal (AC) was evaluated. Shoots were cultured in $1 / 2$ WPM supplemented with $3 \mathrm{mg} \mathrm{l}^{-1}$ IBA for 7 days or $25 \mathrm{mg}^{-1}$ for $24 \mathrm{~h}$. After auxin treatment, shoots were transferred to IBA free root expression medium with $0.4 \%$ AC (Merck, USA). All media were supplemented with $30 \mathrm{~g} \mathrm{l}^{-1}$ sucrose, and $6.5 \mathrm{~g} \mathrm{l}^{-1}$ Vitroagar ( $\mathrm{pH}$ 5.6). The effect of an initial 5-day dark period was also studied. In these experiments, each treatment was evaluated using 12 shoots per treatment, and the experiments were repeated at least three times. The variables determined at the end of the 1-month rooting period were the percentage of shoots that had rooted, the mean number of roots per rooted shoot, and the length of the longest root per rooted shoot.

Shoots with well-developed roots were removed from the culture medium and the roots gently washed under running tap water to remove any traces of medium. The plantlets were then transplanted into $10 \mathrm{~cm}$ diameter plastic pots containing a mixture of garden soil (Terrahum compost, Germany) and perlite (2:1). Potted plants were placed in a growth chamber at a $90 \%$ relative humidity, $25 \pm 2^{\circ} \mathrm{C}$, with a $16 \mathrm{~h}$ photoperiod, and a light intensity of $90-100 \mu \mathrm{mol} \mathrm{m} \mathrm{m}^{-2}$ provided by cool-white fluorescent lamps for 4 weeks. The trays were covered with a transparent plastic tray cover $(18 \times 50 \times 40 \mathrm{~cm})$ that was gradually raised for the plants to adapt. After 4 weeks in these conditions, the plants were transferred to a greenhouse under conditions of natural daylight. Plants were fertilized weekly with $10 \mathrm{ml}$ of Hoagland's solution (Hoagland and Arnon 1941). The survival rates were recorded after 2 months in the greenhouse.

Statistical analysis

The influence of the main experimental factors was evaluated by two-way analysis of variance (ANOVAII). The arcsine square root transformation was applied to proportional data prior to analysis. The data presented in the Tables are untransformed. Tests for normality and homogeneity of variance were performed prior to ANOVA, and least significant difference (LSD) or Dunnett's T3 test $(\mathrm{p} \leq 0.05)$ was used to compare means in the case of homogeneous or non-homogeneous variances, respectively. IBM $^{\circledR}$ SPSS Statistics for Windows 10 (version 21, Chicago, USA) was used for statistical analysis. 


\section{Results}

Establishment stage

After 2-3 weeks in the growth cabinet, flushing occurred in branch segments of the two genotypes providing shoots 1.6-2.1 cm long that had developed from lateral buds or formed accessory buds associated with lateral scars (Fig. 2A). The number of developed shoots was much higher in the CDL genotype than in the SC1, which led to a higher number of initial explants (115 in CDL compared to 43 in SC1) (Table 1).The contamination rates of the initial explants cut from these shoots were, in general, low $(\leq 10 \%)$, which could be attributed to the shoots having been grown in a growth chamber. The transfer of explants to another area of the culture medium appears to have succeeded in limiting the negative effects of exudates. Explants with sprouting buds were obtained in the two genotypes tested, although with marked differences in their in vitro performance. Bud sprouting and shoot growth was slower in SC1, with six months being required to obtain uniformly proliferating cultures (stabilization), compared to two months to stabilize CDL (Table 1). The type of explant used for the initiation of the cultures also had a notable influence on the response, particularly on the CDL genotype. Thus, whereas $44 \%$ of the apical explants responded in vitro (Fig. 2B), this only occurred in the nodal explants in $20 \%$ of case. The percent response in the $\mathrm{SC1}$ genotype was similar for both explant types (Table 1). The greater number of explants with shoots $\geq 5 \mathrm{~mm}$ was obtained with explants of the CDL genotype.

Shoot multiplication stage

Shoots excised from initial explants were subcultured on GD medium supplemented with $0.1 \mathrm{mg} / \mathrm{l} \mathrm{BA}$. Only newly developed shoots exhibiting vigorous growth were used in successive subcultures. In order to improve the multiplication rates, the next sections were performed using shoots of the CDL genotype that, from the beginning, had demonstrated better development and better adaptation to the in vitro propagation conditions.

Influence of the culture medium and the explant type.

The selection of a culture medium is of vital importance for the success of an in vitro process. In $Q$. 
lusitanica, mineral medium and explant type significantly affected the number of shoots $\geq 1 \mathrm{~cm}$, with the highest number (2.7) from nodal explants cultured on WPM $(\mathrm{p} \leq 0.05)$ (Fig $2 \mathrm{C})$. The interaction between mineral medium and explant type was not significant (Table 2). Both factors also significantly influenced the total number of shoots $(\mathrm{p} \leq 0.01)$, but in this case, the interaction between the two factors was significant ( $\mathrm{p} \leq 0.05)$, with the highest number of shoots obtained in WPM and nodal explants (4.0), while apical explants did the same as nodal explants on GD. The longest shoot length ranged from 18.2 to 33.0 $\mathrm{mm}$ and was significantly affected by the mineral medium, but not by the explant type.

The conditions defined in the previous trials were applied in the micropropagation of another genotype of Q. lusitanica ( $\mathrm{SC} 1)$, observing in this case a poor development of the shoots, which remained inactive. The response of the explants in these conditions did not exceed 25-30\%, with lengths of 10 to $15 \mathrm{~mm}$. The increase in the BA concentration to $0.2 \mathrm{mg}^{-1}$ together with the incorporation of $0.5 \mathrm{mg}^{-1}$ IAA and $0.2 \mathrm{mg} \mathrm{l}^{-1}$ of zeatin into the medium significantly improved the development of the shoots. The total number of shoots per explant increased from $1.2 \pm 0.4$ to $2.9 \pm 0.3$ with a mean length of $25 \pm 2.6 \mathrm{~mm}$. Under these conditions, $80 \%$ of the explants responded with elongation of the shoots that achieved lengths of between 2 and $3 \mathrm{~cm}$, making them suitable for subsequent subcultures and rooting

Influence of the orientation of the explant

When the shoots were cultivated in jars in the horizontal position, the number of shoots increased significantly compared to the cultivation of the explants in the vertical position. The interaction of both factors (mineral medium and orientation) was not significant (Table 3). However, approximately $40 \%$ of the explants had shoots with a different morphology, thicker, including some of them with a succulent appearance (Fig. 2D), which made them unsuitable for a subsequent multiplication phase or for their rooting. Based on these results, nodal explants situated in the vertical position in cultivation tubes with WPM were used for the multiplication of $Q$. lusitanica.

Rooting stage

Shoots of 1.5-2.0 $\mathrm{cm}$ of the CDL genotype from the different media used in the multiplication stage (GD, WPM, MS1/2n) were isolated and placed in rooting media. The same media were used in this stage as in the multiplication stage (GD, WPM and MS1/2n) with the macronutrients reduced to $1 / 3(1 / 3 \mathrm{GD})$ or $1 / 2$ (WPM y MS1/2n). The different media were supplemented with IBA $25 \mathrm{mg} \mathrm{l}^{-1}$ for $24 \mathrm{~h}$ or $3 \mathrm{mg} \mathrm{l}^{-1}$ for 7 
days. With both IBA concentrations, the rooting rates were significantly better on the $1 / 2$ WPM medium ( $\mathrm{p} \leq 0.05$; Table 4). However, a high dose/short pulse treatment ( $25 \mathrm{mg}^{-1}$ IBA for $24 \mathrm{~h}$ ) increased the basal callus formation and decreased the number of roots $(\mathrm{p} \leq 0.001)$, which were also shorter, thicker, and with reduced secondary root development. With the $3 \mathrm{mg} \mathrm{l}^{-1}$ IBA treatment, the plants had a more normal morphology, with no basal callus, long roots and a greater presence of secondary roots, which helped in their subsequent acclimatization (Fig. 2E). The interaction between the two factors, culture medium and auxin, was only significant $(\mathrm{p} \leq 0.05)$ for the length of the roots. With low dose/long pulse treatment no significant differences were observed between the different mineral media used, however with the high dose/short pulse treatment, the best results were obtained with 1/2WPM. The incorporation of $0.4 \% \mathrm{AC}$ into the rooting medium significantly enhanced the rooting percentage $(p \leq 0.05)$, the number of roots which developed per shoot $(p \leq 0.01)$, and the length of the longest root $(p \leq 0.001$; Table 5$)$. A further difference observed was that roots developed in the charcoal supplemented medium produced more secondary roots, although this variable was not measured. An initial dark period (5 days) did not improve the outcomes (data not shown), and resulted in deterioration of the quality of the regenerated plants, which exhibited browning and senescence of the apical zone. The roots first became visible from 12-14 days from the beginning of the experiment.

The best conditions defined in previous studies were subsequently used for rooting of shoots from the $\mathrm{SC} 1$ genotype, obtaining rooting percentages of $66.7 \%$ with the low dose/long pulse treatment $\left(3 \mathrm{mg}^{-1}\right.$ IBA for 7 days) and $0.4 \% \mathrm{AC}$ in the rooting expression medium.

Hardening of plantlets in a growth chamber under high humidity for 4 weeks was found to be essential for successful acclimatization. After two months, plantlets were transferred to the greenhouse, and the percentage of surviving plantlets after 4 months was $70 \%$ (Fig. $2 \mathrm{~F}$ ). The rooted plantlets grew well, and appeared healthy.

\section{Discussion}

Plant tissue culture has been used in conservation programs for many species and is especially important in small populations (Gonçalves et al. 2010; Mallón et al. 2010), as is the case of the dwarf oak, which is considered endemic.

In Quercus, Vieitez et al. (2012) pointed out that although the composition of the mineral media was not 
decisive in initiating cultures, Woody Plant Medium (WPM) and Gresshoff and Doy medium (GD) were superior to other mineral media for shoot multiplication cultures. In an experiment carried out to identify the most suitable mineral medium in the multiplication of pedunculated oak, Vieitez et al. (1985) found that the best results of the eight media tested were achieved with GD medium. The authors reported that the use of Murashige and Skoog medium led to poorly developed axillary buds, small leaves, no basal callus formation, and necrosis that spread from the shoot tips to the entire culture. Cultures grown on MS medium also developed thick, succulent, or hyperhydric shoots. The superiority of GD medium was also demonstrated for sessile oak cultures (San José et al. 1990), Q. alba and Q. bicolor (Vieitez et al. 2009), and Q. suber (Romano et al. 1992). However, WPM has been shown to be more efficient for the propagation of other Quercus species (Ostrolucka et al. 2007; Tamta et al. 2008; Vengadesan and Pijut 2009; Pandey and Tamta 2014; Gatti and Sgarbi 2015). In Q. lusitanica the best results were also obtained with WPM, which was significantly superior when nodal explants were used. However, apical explants did the same as nodal explants when GD medium was used. Although half-strength MS macronutrients have given good results for axillary shoot induction in Q. suber (Lebtahi et al. 2015), the lowest multiplication rates were obtained in $Q$. lusitanica using this medium.

The nature of the explant type has been identified by several authors as affecting in vitro performance in the multiplication stage. San José et al. (1990) did not observe any great differences in the multiplication rates depending on the nature of the explant in Q. petraea. However, in a previous work with $Q$. robur, basal and nodal explants performed better than shoot tips (San José et al. 1988). Vieitez et al. (1993a) demonstrated that shoot production in Fagus sylvatica was higher with nodal explants than with apical ones. In this study, nodal explants significantly increased the number of shoots developed when cultured on WPM and MS1/2n.

The cultivation of shoots in the horizontal position has given good results for other Quercus species. Vieitez et al. (2009) showed that the control of efficient shoot multiplication in Q. alba, Q. bicolor, and $Q$. rubra involved the culture of decapitated shoots in a stressful horizontal position on cytokinin-containing medium, as previously reported in Q. robur (San José et al. 1988; Vieitez et al. 1994), Q. rubra (Vieitez et al. 1993b), and Q. petraea (San José et al. 1990). Its action in promoting axillary shoots is believed to result from the altered distribution of growth regulators and greater uptake of medium constituents (Mackay and Kitto 1988). This mechanical stress could favor the synthesis of ethylene and its accumulation in the atmosphere of the culture vessel (Anten et al. 2006). The availability of endogenously 
regulated ethylene is essential for the released bud on a decapitated plant, in order to sustain its subsequent development into a lateral shoot, possibly acting by reducing auxin transport (Yeang and Hillman 1984). In Q. lusitanica, the horizontal culture of shoots appeared to improve the multiplication rate in both GD and WPM media. However, the shoots produced in the horizontal culture has a succulent appearance, which made their subsequent multiplication and rooting difficult.

In the present study, as in those of other tree species (Vieitez et al. 2012), the success of in vitro shoot proliferation depended on genotype, with the protocols needing to be adapted in order to achieve better micropropagation conditions. Thus, while in the CDL genotype, the best results were obtained with the WPM medium supplemented with BA $0.1 \mathrm{mg} \mathrm{l}^{-1}$, in the case of genotype $\mathrm{SC} 1$, the BA concentration needed to be increased at $0.2 \mathrm{mg} \mathrm{l}^{-1}$, as well as adding IAA and zeatin to the medium, in order to increase the elongation of the shoots, and with this, the proliferation rates. The combination of BA and IAA has also given good results in the proliferation and elongation of shoots in other oak species, such as $Q$. suber (Romano et al. 2003) and Q. serrata (Pandey and Tamta 2014). Furthermore, the incorporation of zeatin in the multiplication medium favors the elongation of the shoots. The in vitro growth of leaves and shoots of beech (Vieitez et al. 2003), Quercus alba and Q. bicolor (Vieitez et al. 2009), and black alder (San José et al. 2013) was better with BA and zeatin. According to these authors, their results suggested the occurrence of a possible imbalance in the levels of endogenous zeatin, or its different derivatives, in shoots of these species cultured in the presence of BA-supplemented medium. These results also agree with those of Werner et al. (2001), who observed that the growth of tobacco leaves required a fine adjustment of natural cytokinin levels. Genotypes appear to differ significantly in their physiological requirements for maximum shoot proliferation and elongation, indicating that clonal effects need to be considered in future attempts to micropropagate $Q$. lusitanica

Vieitez et al. (2012) mentioned different methods for the rooting of the shoots of different oak species, such as the addition of IBA or naphthalene acetic acid for a period of 7-8 days, dipping the basal ends of the shoots in highly concentrated solutions of IBA, or the culture of shoots in media containing $25 \mathrm{mg} / \mathrm{l}^{-1}$ IBA for 24-48 h. High dose/short pulse treatments (IBA $25 \mathrm{mg} \mathrm{l}^{-1}$ for $24,48 \mathrm{~h}$ ) are habitually used with success in the rooting of other oak species: Q. robur and Q. rubra (Sánchez et al. 1996), Q. rubra (Vengadesan and Pijut 2009), Q. alba, Q. bicolor and Q. rubra (Vieitez et al. 2009), and Q. aliena (Liao and Chuang 2014); while it helped to obtain elevated percentages of response in Q. lusitanica, it led to the development of basal callus, dryness of the apices and abnormal thick roots, and with no secondary ones. 
Proliferating callus tissues will delay or disrupt the establishment of vascular connections. The formation of basal callus is considered to be detrimental for subsequent survival of plantlets during acclimatization. The callus also represents a sink that may deprive the shoot axis of adequate supplies of nutrients or growth factors, and thus compromises the survival of plantlets (Puddephat et al. 1999). The low dose/long pulse treatment favours the development of the roots, which had a more normal morphology and a greater presence of secondary roots that favoured the subsequent plantlet acclimatization.

The incorporation of $\mathrm{AC}$ in the rooting medium significantly increased the rooting percentages, and favored the development of secondary roots in both genotypes. Vieitez et al. (2009) also pointed out that the addition of $\mathrm{AC}(0.4 \%)$ to the rooting medium improved both the quality of the shoots and the development of the roots, which have a better lateral root formation. Gatti and Sgarbi (2015) indicated that the addition of $\mathrm{AC}(0.2 \%)$ to the culture medium prevented shoot browning. These effects of AC are attributed to the adsorption of the excess of growth regulators or detrimental substances that may be released by the plant tissue or by the medium (Thomas 2008).

Although different authors (Romano and Martins-Louçao 2003; Pandey and Tamta 2014) point out that the application of darkness during the first step of rooting showed a positive effect on rooting frequency, in the case of dwarf oak, as well as other species of oak (Vieitez et al. 2009), it acted in detriment to the quality of the rooted plants.

It should be mentioned that the rooting percentages achieved in this work are much higher than those described by Fernández Rodríguez et al. (2005) who studied the rooting of dwarf oak cuttings of 6-8 cm with a $1-2 \%$ solution of IBA. These authors observed wide differences in the results between the ten genotypes studied; whilst in some cases the rooting percentage was $40 \%$, in other genotypes it varied between $3.3 \%$ and $6 \%$. Genotype differences have been observed in other species, such as American oaks (Vieitez et al. 2009) or Alnus glutinosa (San José et al. 2013)

\section{Conclusion}

In conclusion, this is the first study that defines a simple protocol for micropropagation of the threatened species $Q$. lusitanica via the proliferation of axillary shoots, using a high-frequency rooting and acclimatization protocol. These results appear to indicate good potential for the application of micropropagation techniques in dwarf oak of mature origin. The micropropagation technology developed 
in this study offers excellent opportunities and tools for rapid replenishment and conservation of dwarf oaks in their natural environment, and provides a platform for further research into this emblematic endangered species.

\section{Acknowledgments}

We thank the Asociación Monte Pindo Parque Natural (AMPPN) and Dr EV Carral for kindly providing the plant material used in this study, and Dr S González Prieto for providing the photos of the trees. Thanks are also given to Mr JC Suárez San Martín and N Blázquez for their technical support.

\section{References}

Anten NPR, Casado-García R, Pierik R, Pons TL (2006) Ethylene sensitivity affects changes in growth patterns, but not stem properties, in response to mechanical stress in tobacco. Physiol Plant 128:274-282

Bunn E (2005) Development of in vitro methods for ex situ conservation of Eucalyptus impensa, an endangered malle from southwest Western Australia. Plant Cell Tissue Organ Cult 83:97-102

Cabezudo B, Talavera S, Blanca G, Salazar C, Cueto M, Valdés B, Hernández-Bermejo JE, Herrera CM, Rodríguez Hiraldo C, Navas D (2005) Lista roja de la flora vascular de Andalucía. Consejería de medio ambiente. Junta de Andalucía

Fay MF (1992) Conservation of rare and endangered plants using in vitro methods. In Vitro Cell Dev Biol Plant 28:1-4

Fernández Rodríguez R, Faria C, Matzen J, Simões F, Almeida MH, Rigueiro Rodríguez A (2005) Identificación mediante técnicas moleculares de Quercus lusitanica Lam. y estudio de técnicas de propagación como base para la conservación de esta especie. $5^{\circ}$ Congreso Forestal Nacional. Viseu, Portugal

Gatti E, Sgarbi E (2015) Micropropagation of Quercus robur explant sources and cultural conditions affect in vitro responses differently. Acta Hortic 1083:303-310

Gonçalves S, Fernandes L, Romano A (2010) High-frequency in vitro propagation of the endangered species Tuberaria major. Plant Cell Tissue Organ Cult 101:359-363 
Gresshoff PM, Doy CH (1972) Development and differentiation of haploid Lycopersicon esculentum. Planta 107: 161-170

Guo B, Gao M, Liu CZ (2007) In vitro propagation of an endangered medicinal plant Saussurea involucrata Kar. et Kir. Plant Cell Rep 26:261-265

Hill P, Gutierrez L, Carmack L, Kopp OR (2015) Micropropagation of Astragalus holgreniorum (Holmgren milkvetch), and endemic and endangered species. Plant Cell Tissue Organ Cult 121: 381-387

Hoagland DR, Arnon DI (1941) The water culture method for growing plants without soil. Miscellaneous Publications 3515. Circular of the California Agricultural Experimental Station 347-361

Jayaram K, Prasad MNV (2007) Rapid in vitro multiplication of Drosera indica L.: a vulnerable, insectivorous plant. Plant Biotechnol Rep 1:79-84

Lebtahi F, Errahmani MB, Bouguedoura N (2015) Propagation of cork oak (Quercus suber L.) by axillary shoot and somatic embryogenesis. Propag Ornam Plants 15:113-122

Liao YK, Chuang MC (2014) Micropropagation of Quercus aliena var. aliena from explants of mature trees. Taiwan J Forest Sci 29:117-131

Lloyd G, McCown B (1980) Commercially-feasible micropropagation of mountain laurel, Kalmia latifolia, by use of shoot-tip culture. Comb Proc Int Plant Prop Soc 30:421-427

Mackay WA, Kitto SL (1988) Factors affecting in vitro shoot proliferation of French Tarragon. J Amer Soc Hortic Sci 2:282-287

Mallón R, Rodríguez-Oubiña J, González ML (2010) In vitro propagation of the endangered plant Centaurea ultreiae: assessment of genetic stability by cytological studies, flow cytometry and RAPD analysis. Plant Cell Tissue Organ Cult 101:31-39

Muliawan SY, Kit LS, Devi S, Hashim O, Yusof R (2006) Inhibitory potential of Quercus lusitanica extract on Dengue virus type 2 replication. Southeast Asian J Trop Med Public Health 37: 132-135

Murashige T, Skoog F (1962) A revised medium for rapid growth and bioassays with tobacco tissue culture. Physiol Plant 15:473-497 
Ostrolucká MG, Gajdosová A, Libiaková G (2007) Protocol for micropropagation of Quercus spp. In: Jain SM, Häggman (eds) Protocols for micropropagation of woody trees and fruits. Springer, The Netherlands, pp 85-91

Pandey A, Tamta S (2014) In vitro propagation of the important tasar oak (Quercus serrata Thunb.) by casein hydrolysate promoted high frequency shoot proliferation. J Sustain Forest 33:590-603

Pence VC (2013) In vitro methods and the challenge of exceptional species for target 8 of the global strategy for plant conservation. Ann Miss Bot Gard 99: 214-220

Piovan A, Caniato R, Mariella Cappelletti E, Filippini R (2010) Organogenesis from shoot segments and via callus of endangered Kosteletzkya pentacarpos (L.) Ledeb. Plant Cell Tissue Organ Cult 100:309-315

Puddephat IJ, Alderson PG, Wright NA (1999) In vitro root induction in axillary microshoots of Quercus robur L. Ann Appl Biol 134:233-239

Romano A, Martins-Louçao MA (2003) Strategies to improve rooting and acclimatization of cork oak. Acta Hortic 616:275-278

Romano A, Noronha C, Martins-Louçao MA (1992) Influence of growth regulators on shoot proliferation in Quercus suber L. Ann Bot 70:531-536

San José MC, Ballester A, Vieitez AM (1988) Factors affecting in vitro propagation of Quercus robur L. Tree Physiol 4:281-290

San José MC, Janeiro LV, Corredoira E (2013) Micropropagation of threatened black alder. Silva Fenn $47: 1-12$

San José MC, Vieitez AM, Ballester A (1990) Clonal propagation of juvenile and adult trees of sessile oak by tissue culture. Silvae Genet 39:50-55

Sánchez MC, San José MC, Ballester A, Vieitez AM (1996) Requirements for in vitro rooting of Quercus robur and Q. rubra shoots derived from mature trees. Tree Physiol 16:673-680

Sarasan V, Cripps R, Ramsay MM, Atherton C, McMichen M, Prendergast G, Rowntree JK (2006) Conservation in vitro of threatened plants-Progress in the past decade. In Vitro Cell Dev Biol Plant 42:206-214 
Tamta S, Palni LM, Purohit VK, Nandi SK (2008) In vitro propagation of brown oak (Quercus semecarpifolia Sm.) from seedling explants. In Vitro Cell Dev Biol Plant 44:136-141

Thomas TD (2008) The role of activated charcoal in plant tissue culture. Biotechnol Adv 26: 618-631

Vázquez FM, Gutiérrez M, Blanco J, García D, Guerra MJ, Márquez F, Cabeza de Vaca MA, López JL, Sánchez A, Palacios MJ, Mateos JA (2010) Catálogo regional de especies vegetales amenazadas de Extremadura. Junta de Extremadura

Vengadesan G, Pijut PM (2009) Somatic embryogenesis and plant regeneration of northern red oak (Quercus rubra L.). Plant Cell Tissue Organ Cult 97:141-149

Vieitez AM, Corredoira E, Ballester A, Muñoz F, Durán J, Ibarra M (2009) In vitro regeneration of important North American oak species Quercus alba, Quercus bicolor, Quercus rubra. Plant Cell Tissue Organ Cult 98:135-145

Vieitez AM, Corredoira E, Martínez MT, San José MC, Sánchez C, Valladares S, Vidal N, Ballester A (2012). Application of biotechnological tools to Quercus improvement. Eur J Forest Res 131:519-539

Vieitez AM, Ferro EM, Ballester A (1993a) Micropropagation of Fagus sylvatica L. In Vitro Cell Dev Biol Plant 29:183-188

Vieitez AM, Pintos F, San José MC, Ballester A (1993b) In vitro shoot proliferation determined by explant orientation of juvenile and mature Quercus rubra L. Tree Phsyiol 12:107-117

Vieitez AM, San José MC, Sánchez C, Ballester A (2003) Micropropagation of Fagus spp. In: Jain SM, Ishii K (eds) Micropropagation of woody trees and fruits. Kluwer, Dordrecht, pp 181-215

Vieitez AM, San José MC, Vieitez E (1985) In vitro plantlet regeneration from juvenile and mature Quercus robur L. J Hortic Sci 60:99-106

Vieitez AM, Sánchez MC, Amomarco JB, Ballester A (1994) Forced flushing of branch segments as a method for obtaining reactive explants of mature Quercus robur trees for micropropagation. Plant Cell Tissue Organ Cult 37:287-295

Werner T, Motyka V, Strnad M, Schmülling T (2001) Regulation of plant growth by citokynin. Proc Nat Acad Sci 98:10487-10492 
Wildi E, Schaffner W, Berger Büter K (1998) In vitro propagation of Petasites hybridus (Asteraceae) from leaf and petiole explants and from inflorescence buds. Plant Cell Rep 18:336-340

Yeang HY, Hillman JR (1984) Ethylene and apical dominance. Physiol Plant 60:275-282

\section{Legend of figures}

Fig. 1. Quercus lusitanica Lam. growing in Monte Pindo (La Coruña, Spain) that were used as the sources of explants to initiate the cultures. A and B. Genotypes CDL and SC1, respectively

Fig. 2. Micropropagation of Quercus lusitanica Lam. (genotype CDL). A. Forced flushing of branch segments in the growth chamber. B. Stabilization of cultures from apical explants. C. Shoot multiplication after culture in WPM medium supplemented with $0.1 \mathrm{mg}^{-1}$ BA. D. Shoot proliferation cultures in horizontal position. E. Rooting of shoots in $1 / 2$ WPM supplemented with IBA $3 \mathrm{mg}^{-1}$ for 7 days. F. Acclimatized plants 8 weeks old 


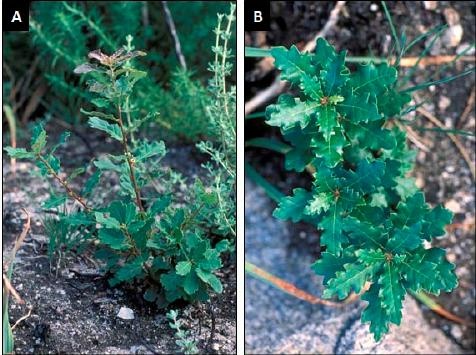




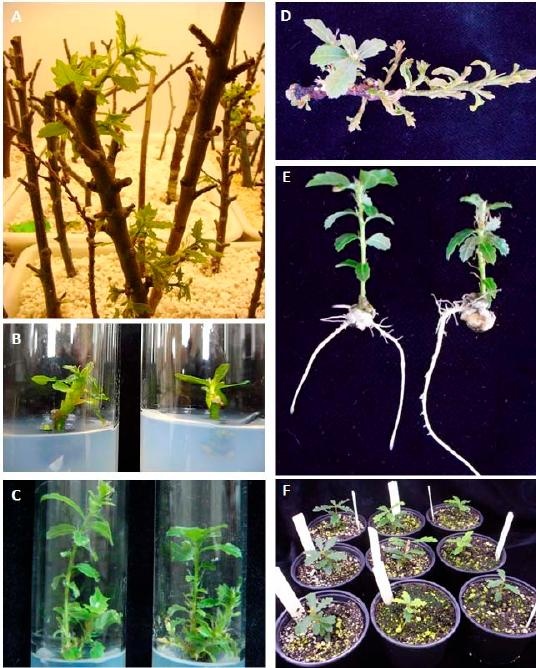


Table 1. In vitro establishment of Quercus lusitanica Lam. (genotypes CDL and SC1)

\begin{tabular}{|c|c|c|c|c|c|c|c|c|c|c|c|c|}
\hline \multirow[t]{2}{*}{ Genotype } & \multicolumn{4}{|c|}{ Flushing capacity $^{1}$} & \multicolumn{8}{|c|}{ Response to in vitro establishment } \\
\hline & $\begin{array}{l}\text { Branch } \\
\text { number }\end{array}$ & $\begin{array}{l}\text { Diameter } \\
(\mathrm{mm})\end{array}$ & $\mathrm{N}^{\mathrm{o}}$ shoots & $\begin{array}{c}\text { Lenght of } \\
\text { shoots }(\mathrm{mm})\end{array}$ & $\begin{array}{c}\mathrm{N}^{\circ} \text { of initial } \\
\text { explants }\end{array}$ & $\begin{array}{l}\text { Contamination } \\
\text { rate }(\%)^{2}\end{array}$ & & is rate & & $\begin{array}{l}\%)^{2} \\
\% s e\end{array}$ & $\begin{array}{l}\text { Explants } \\
\text { with shoots } \\
\geq 5 \mathrm{~mm}^{2}\end{array}$ & $\begin{array}{c}\text { Period } \\
\text { needed for } \\
\text { stabilization } \\
\text { (months) }\end{array}$ \\
\hline \multirow[t]{2}{*}{$\mathrm{CDL}$} & 15 & $4-11$ & 50 & 21.2 & 115 & 8.7 & $\mathrm{~A}$ & 56.0 & $\mathrm{~A}$ & 44.0 & 22 & 2 \\
\hline & & & & & & & $\mathrm{N}$ & 80.0 & $\mathrm{~N}$ & 20.0 & 10 & \\
\hline \multirow[t]{2}{*}{ SC1 } & 26 & $5-15$ & 21 & 15.8 & 43 & 9.3 & A & 50.0 & A & 50.0 & 10 & 6 \\
\hline & & & & & & & $\mathrm{N}$ & 33.3 & $\mathrm{~N}$ & 66.6 & 12 & \\
\hline
\end{tabular}

${ }^{1}$ Evaluated after 4 weeks on growth chamber. ${ }^{2}$ Evaluated after 8 weeks of culture. ${ }^{3}$ Explants with sprouting buds after 8 weeks culture. A: apical segments. N: nodal segments. 
Table 2. In vitro proliferation of Quercus lusitanica Lam. (genotype CDL)

\begin{tabular}{|c|c|c|c|c|c|c|c|c|c|c|c|c|}
\hline \multirow[t]{2}{*}{ Mineral medium } & \multicolumn{2}{|c|}{$\begin{array}{c}\text { Responsive explants } \\
(\%)\end{array}$} & \multicolumn{3}{|c|}{ Number of shoots $\geq 1 \mathrm{~cm}$} & \multicolumn{2}{|c|}{$\begin{array}{c}\text { Number of shoots } \\
0.5-1.0 \mathrm{~cm}\end{array}$} & \multicolumn{2}{|c|}{ Total number of shoots } & \multicolumn{3}{|c|}{ Longest shoot length (mm) } \\
\hline & Apex & Node & Apex & Node & Mean & Apex & Node & Apex & Node & Apex & Node & Mean \\
\hline GD & $95.8 \pm 0.1$ & $93.8 \pm 0.1$ & $1.6 \pm 0.3$ & $1.5 \pm 0.3$ & $1.5 \pm 0.1 a^{I}$ & $0.9 \pm 0.4$ & $1.0 \pm 0.2$ & $2.6 \pm 0.3 b$ & $2.5 \pm 0.2 b$ & $21.2 \pm 2.7$ & $20.2 \pm 2.7$ & $20.7 \pm 2.4 a$ \\
\hline WPM & $100 \pm 0.0$ & $100 \pm 0.0$ & $1.6 \pm 0.3$ & $2.7 \pm 0.4$ & $2.1 \pm 0.5 b$ & $0.7 \pm 0.2$ & $1.3 \pm 0.6$ & $2.3 \pm 0.3 b$ & $4.0 \pm 0.3 c$ & $31.6 \pm 4.3$ & $33.0 \pm 2.8$ & $32.3 \pm 3.2 b$ \\
\hline Mean & & & $1.4 \pm 0.3 a$ & $2.0 \pm 0.4 b$ & & & & & & & & \\
\hline \multicolumn{13}{|l|}{$F$-test } \\
\hline Mineral medium (A) & \multicolumn{2}{|c|}{$\mathrm{ns}^{2}$} & \multicolumn{3}{|c|}{$\mathrm{p} \leq 0.05$} & \multicolumn{2}{|c|}{$\mathrm{ns}$} & \multicolumn{2}{|c|}{$\mathrm{p} \leq 0.01$} & \multicolumn{3}{|c|}{$\mathrm{p} \leq 0.01$} \\
\hline Explant type (B) & \multicolumn{2}{|c|}{ ns } & & $\mathrm{p} \leq 0.05$ & & \multicolumn{2}{|c|}{$\mathrm{ns}$} & \multicolumn{2}{|c|}{$\mathrm{p} \leq 0.01$} & \multicolumn{3}{|c|}{ ns } \\
\hline
\end{tabular}

Each value represents the mean \pm standard error (SE) of three replications with twelve explants in each replicate. Statistical significance $(P$-values) of the terms of a two-way ANOVA with mineral medium and explant type as the two main factors. ${ }^{1}$ Means followed by different letters indicate significant differences between proliferation media. ${ }^{2}$ ns, not significant. 